\title{
Gas release-based prescreening combined with reversed-phase HPLC quantitation for efficient selection of high-y-aminobutyric acid (GABA)-producing lactic acid bacteria
}

\author{
Qinglong Wu and Nagendra P. Shah ${ }^{1}$ \\ Food and Nutritional Science, School of Biological Sciences, The University of Hong Kong, Pokfulam Road, Hong Kong
}

\begin{abstract}
High $\gamma$-aminobutyric acid (GABA)-producing lactobacilli are promising for the manufacture of GABA-rich foods and to synthesize GRAS (generally recognized as safe)-grade GABA. However, common chromatography-based screening is time-consuming and inefficient. In the present study, Korean kimchi was used as a model of lactic acid-based fermented foods, and a gas release-based prescreening of potential GABA producers was developed. The ability to produce GABA by potential GABA producers in de Man, Rogosa, and Sharpe medium supplemented with or without monosodium glutamate was further determined by HPLC. Based on the results, 9 isolates were regarded as high GABA producers, and were further genetically identified as Lactobacillus brevis based on the sequences of 16S rRNA gene. Gas release-based prescreening combined with reversed-phase HPLC confirmation was an efficient and cost-effective method to identify high-GABA-producing LAB, which could be good candidates for probiotics. The GABA that is naturally produced by these high-GABA-producing LAB could be used as a food additive.
\end{abstract}

Key words: $\gamma$-aminobutyric acid, lactic acid bacteria, carbon dioxide, reversed-phase HPLC

\section{INTRODUCTION}

$\gamma$-Aminobutyric acid (GABA), a nonprotein amino acid, is the major inhibitory neurotransmitter of central nervous system; it is found mainly in the brain and regulates many physiological and psychological behaviors. Both GABA and GABA-rich foods have shown antianxiety and antidepressant activities (Krystal et al., 2002; Cryan and Kaupmann, 2005; Chuang et al., 2011), antihypertensive effects (Hayakawa et al., 2002; Inoue et al., 2003; Yoshimura et al., 2010; Liu et al.,

Received September 1, 2014.

Accepted November 8, 2014.

${ }^{1}$ Corresponding author: npshah@hku.hk
2011), and regulation of hormone secretion (GamelDidelon et al., 2002; Constantin et al., 2010). In China and Japan, generally recognized as safe (GRAS)-grade GABA has been approved as a functional food additive. Subsequently, GABA-rich foods have been developed by using GABA-producing microorganisms (Inoue et al., 2003; Rizzello et al., 2008; Sun et al., 2009; Yoshimura et al., 2010; Liu et al., 2011; Nejati et al., 2013) and are popular.

$\gamma$-Aminobutyric acid is widely distributed in mammals and plants but GABA is usually present in small amounts. Interest is growing in the use of GABA-producing microorganisms with food-grade status for manufacturing GABA-rich foods. High-GABA-producing lactic acid bacteria (LAB) are promising candidates as starter cultures for food fermentation and as cell factories for the synthesis of GRAS-grade GABA (Li and Cao, 2010). Recently, high-GABA-producing Lactobacillus species were applied in the dairy industry to manufacture GABA-rich yogurt and related products (Inoue et al., 2003; Sun et al., 2009; Liu et al., 2011; Nejati et al., 2013). So far, several strains of highGABA-producing LAB have been isolated, including Lactobacillus brevis NCL912 from Chinese paocai (Li et al., 2008), L. brevis TCCC13007 from Chinese pickled vegetables (Zhang et al., 2012), L. brevis $\mathrm{BH} 2$, L. brevis K203, and L. brevis OPK-3 from Korean kimchi (Kim et al., 2007; Park and Oh, 2007; Binh et al., 2014), L. brevis DPC6108 from Irish infant feces (Barrett et al., 2012), L. brevis IFO12005 from Japanese alcoholic beverages (Yokoyama et al., 2002), Lactobacillus paracasei NFRI 7415 from Japanese fermented fish (Komatsuzaki et al., 2005), and L. brevis CGMCC 1306 from Italian unpasteurized milk (Fan et al., 2012). Species of $L$. brevis appear to show the most potential for producing large amounts of GABA (Li and Cao, 2010). Acid-based fermented foods, such as Korean kimchi and Chinese paocai, are natural habitats for GABA-producing LAB. This may be due to the presence of the glutamateGABA system in these foods; this system reduces protons by decarboxylation of glutamate into GABA, which contributes to bacterial acid resistance (De Biase and Pennacchietti, 2012; Teixeira et al., 2014). 
Because GABA production from LAB is strain specific, screening of high-GABA-producing LAB from numerous isolates is time consuming. In previous reports, chromatography-based screening, such as HPLC, amino acid analyzer, and thin layer chromatography (TLC), were widely used (Li et al., 2008; Li and Cao, 2010). However, chromatography-based methods have some shortcomings, such as tedious sample preparation and low throughput, resulting in a time-consuming and inefficient process ( $\mathrm{Li}$ and Cao, 2010). To date, only limited studies have been carried out to improve the screening for GABA-producing LAB. In the current study, Korean kimchi was used as a model of lactic acid-based fermented food, a prescreening method based on gas release was developed to identify potential high-GABA producers, and their GABA-producing ability was further determined by HPLC.

\section{MATERIALS AND METHODS}

\section{Acid Treatment and Gas Release-Based Prescreening Procedure}

The experimental process of acid treatment for harvested bacteria is shown in Figure 1. After acid treatment, the treated bacterial mixture was spread plated on to de Man, Rogosa, and Sharpe (MRS) agar and incubated at $37^{\circ} \mathrm{C}$ for $24 \mathrm{~h}$ to obtain individual colonies. Selected colonies were inoculated in MRS medium containing $10 \mathrm{~g} / \mathrm{L}$ of monosodium glutamate (MSG) in centrifuge tubes and statically incubated at $37^{\circ} \mathrm{C}$ for $24 \mathrm{~h}$. Isolates that showed gas release after gentle pipetting and releasing the medium a few times were considered potential high GABA producers. Attention must be paid to this procedure to ensure that any air in the tip before pipetting is not introduced (air can be largely removed by pipetting down). The action of pipetting up and down must be slow and gentle; otherwise, bubbles will form because of the gas released from broth.

\section{Fermentation Conditions for GABA Production}

The ability to produce GABA by all potential high GABA producers was evaluated in MRS broth containing various concentrations of MSG. The MRS broth and MSG were autoclaved separately to avoid the Maillard reaction and reduction of MSG before mixing. One percent fresh bacterial culture $\left(1 \times 10^{9} \mathrm{cfu} / \mathrm{mL}\right)$ was inoculated into $10 \mathrm{~mL}$ of MRS medium containing 0 , $10,30,50$, or $70 \mathrm{~g} / \mathrm{L}$ of MSG and incubated aerobically at $37^{\circ} \mathrm{C}$ for $72 \mathrm{~h}$. The concentration of GABA in MRS medium was monitored by reversed-phase HPLC every

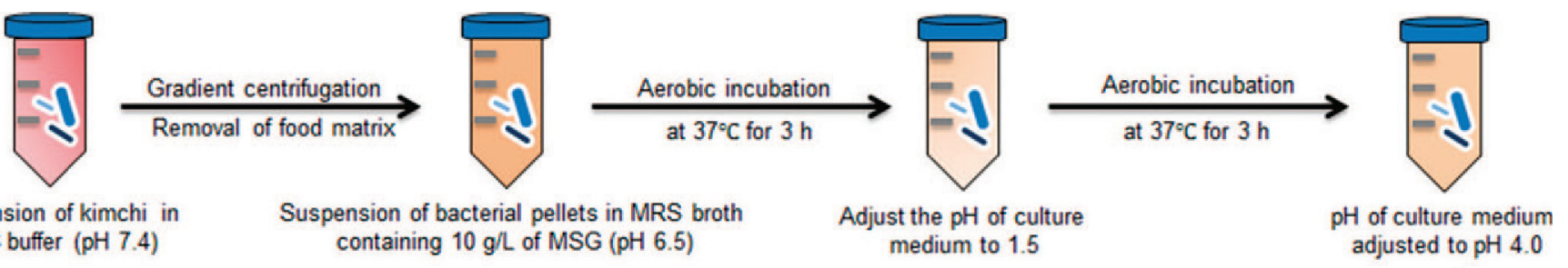
Suspension of kimchi in
PBS buffer ( $\mathrm{pH} 7.4$ ) containing $10 \mathrm{~g} / \mathrm{L}$ of MSG (pH 6.5) medium to 1.5
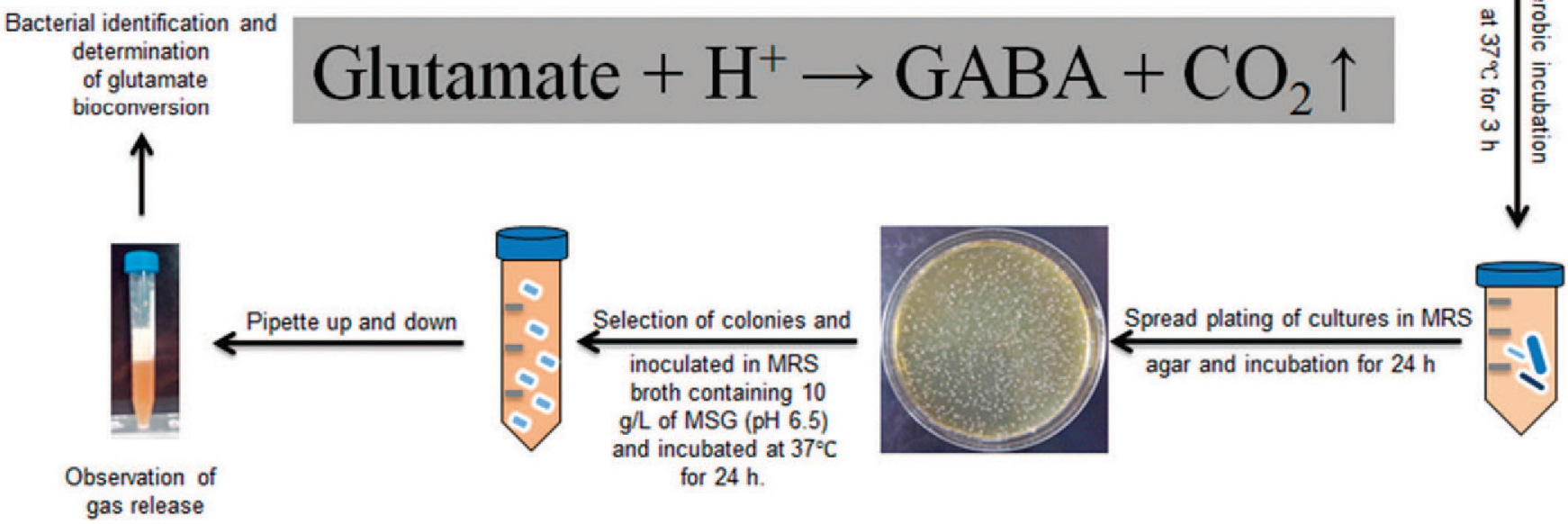
gas release for $24 \mathrm{~h}$.

Figure 1. Flow diagram of acid treatment of bacteria harvested from Korean kimchi and gas release-based screening procedure. MRS $=$ de Man, Rogosa, and Sharpe medium; MSG $=$ monosodium glutamate; GABA $=\gamma$-aminobutyric acid. Color version available online. 
$24 \mathrm{~h}$. Three independent fermentations were carried out for each potential high GABA producer.

\section{Determination of GABA Production by Reversed-Phase HPLC}

Aliquots of MRS cultures were centrifuged at 12,000 $\times g$ for 10 min at room temperature to remove bacterial cells, and the supernatants were collected for dansyl derivatization. The preparation of dansyl AA was performed according to Le Vo et al. (2012). If the concentrations of MSG and GABA were too high, the supernatants were diluted 10-fold for the dansylation reaction.

Dansyl AA including dansyl GABA and dansyl glutamic acid were completely separated and quantified by reversed-phase HPLC (Shimadzu model LC-2010A, Shimadzu Corp., Kyoto, Japan) using a Kromasil 5- $\mu$ m $100 \mathrm{~A}$ C18 column $(250 \mathrm{~mm} \times 4.6 \mathrm{~mm}$; Phenomenex, Torrance, CA). Here, we developed a new separation program for dansyl AA by using 2 mobile phases: A (30 $\mathrm{m} M$ ammonium acetate, $\mathrm{pH}$ 7.5) and $\mathrm{B}$ (acetonitrile). The column was eluted with a linear gradient of 6 to $10 \% \mathrm{~B}$ over 0 to $5 \mathrm{~min}, 10$ to $18 \% \mathrm{~B}$ over 5 to $7 \mathrm{~min}, 18$ to $22 \%$ B over 7 to $15 \mathrm{~min}, 22$ to $26 \%$ B over 15 to 18.5 min, 26 to $28.5 \%$ B over 18.5 to $22.5 \mathrm{~min}, 28.5$ to $30 \%$ B over 22.5 to $24 \mathrm{~min}, 30$ to $32 \%$ B over 24 to $27.5 \mathrm{~min}$, 32 to $55 \%$ B over 27.5 to $40 \mathrm{~min}, 55$ to $50 \%$ B over 40 to $45 \mathrm{~min}, 50$ to $6 \% \mathrm{~B}$ over 45 to $48 \mathrm{~min}$, and held at $6 \% \mathrm{~B}$ for $2 \mathrm{~min}$. The flow rate of the mobile phase was $1 \mathrm{~mL} / \mathrm{min}$. Samples were injected at a volume of $20 \mu \mathrm{L}$ and were detected by absorbance of $275 \mathrm{~nm}$. The oven temperature was maintained at $30^{\circ} \mathrm{C}$.

\section{S rRNA Gene Sequencing}

Genomic DNA from high GABA producers was extracted using ChargeSwitch gDNA mini bacteria kit (Invitrogen, Carlsbad, CA) according to the manufacturer's instructions. Bacteria-specific primer $27 \mathrm{~F}$ (5'-agagtttgatcatgcctcag-3') and universal primer 1492R (5'-ggttaccttgttacgactt-3') were used to amplify the 16S rRNA gene (Marchesi et al., 1998). After amplification, PCR products were purified, ligated into T-vector, and transformed into competent Escherichia coli DH5a. Successful transformants were chosen for Sanger sequencing after the selection procedure.

\section{RESULTS}

\section{Gas Release-Based Prescreening}

Based on the gas release phenomenon, 9 isolates were identified as potential high GABA producers from 500 randomly selected individual colonies. The principle for this screening method is production of $\mathrm{CO}_{2}$ during decarboxylation of MSG (Figure 1). Because high GABA producers are rare in environments, it is not recommended to use chromatography-based techniques to determine the GABA yield in samples if all colonies are selected to inoculate in MRS broth containing MSG for incubation due to the substantial effort and high cost required for screening. This prescreening method based on gas release was efficient and cost effective in identifying potential high GABA producers.

\section{Profiling of AA Using Reversed-Phase HPLC}

Because there is a very small amount of glutamate in MRS medium, additional MSG is normally added as a substrate for GABA production. Separation and quantitation of 21 dansyl AA by reversed-phase HPLC was successful (chromatogram D, Figure 2). The production of GABA was increased by decarboxylation of MSG by high GABA producers in MRS medium supplemented with MSG (chromatograms A and B, Figure 2). $\mathrm{A} \mathrm{CO}_{2}$-producing L. fermentum $\mathrm{W} 8$ was used as a control for the gas release phenomenon. However, the production of $\mathrm{CO}_{2}$ by $L$. fermentum W8 is mainly due to heterofermentation of glucose (Mayo et al., 2010). Its AA profile in MRS medium supplemented with 10 $\mathrm{g} / \mathrm{L}$ of MSG after $24 \mathrm{~h}$ fermentation was evaluated but GABA production by $L$. fermentum W8 was not observed (chromatogram C, Figure 2). It was clear that L. fermentum $\mathrm{W} 8$ is not a GABA producer.

\section{Effects of MSG Supplementation and Incubation Time on GABA Production}

The production of GABA by 9 potential GABA producers at various MSG concentrations and incubation times is shown in Table 1. The bioconversion rates of all $9 \mathrm{LAB}$ isolates were above $95.42 \%$ (with $10 \mathrm{~g} / \mathrm{L} \mathrm{MSG}$ and incubation time of $24 \mathrm{~h}$ ), $78.77 \%$ (30 g/L MSG, 48 h), $62.45 \%$ (50 g/L MSG, $72 \mathrm{~h})$, and $41.45 \%(70 \mathrm{~g} / \mathrm{L}$ MSG, $72 \mathrm{~h}$ ). In particular, isolate NPS-QW-255 showed the lowest conversion rate and isolate NPS-QW-171 showed the second lowest; however, their conversion rates were still high compared with the reported highGABA-producing LAB strains (Li and Cao, 2010). A slight decrease in GABA was observed in most strains after $72 \mathrm{~h}$ of fermentation compared with that at $48 \mathrm{~h}$.

\section{Molecular Taxonomy of GABA Producers Based on the 16S rRNA Gene}

The 9 potential high GABA producers were identified by $16 \mathrm{~S}$ rRNA gene identification. Results of agarose gel 


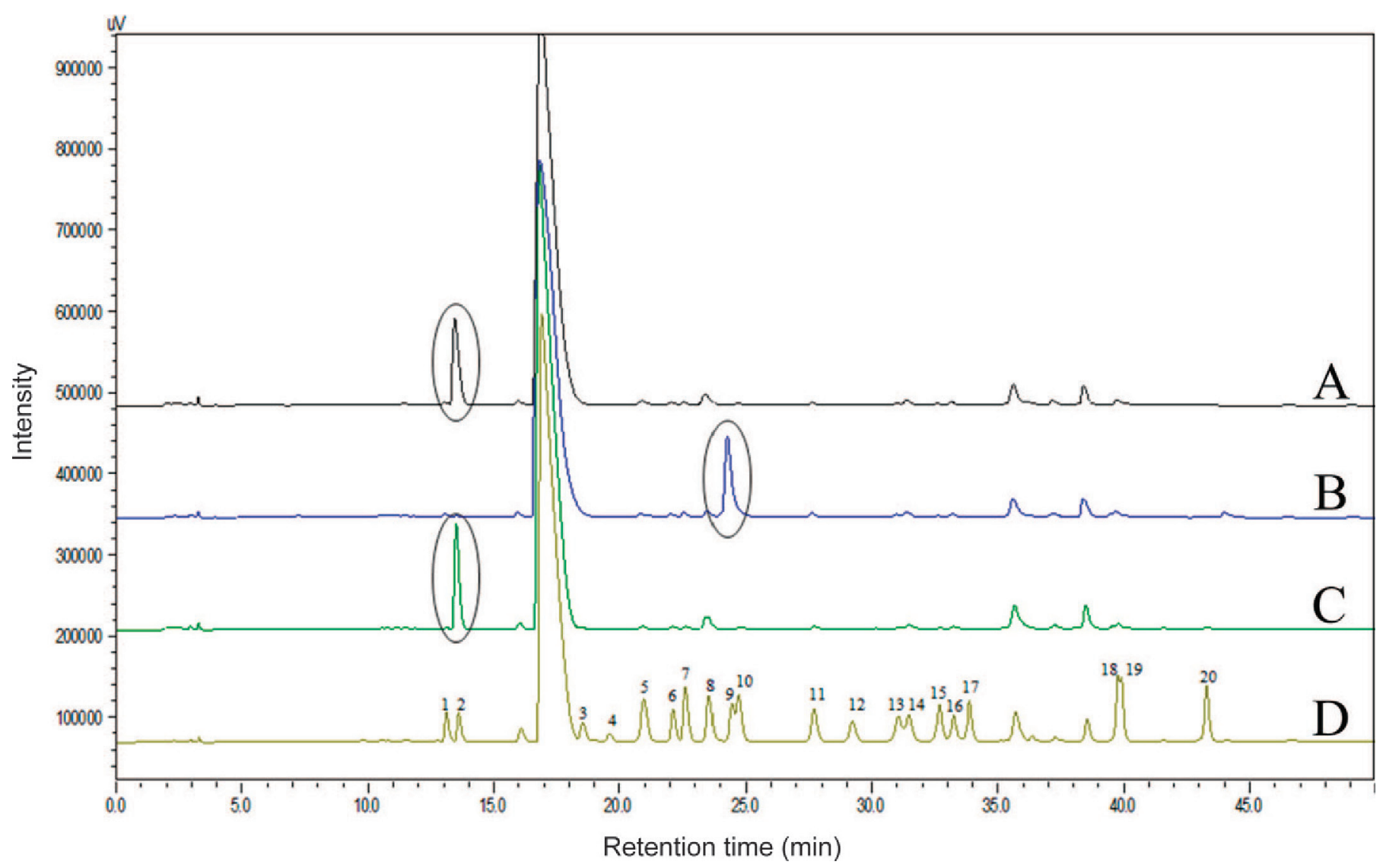

Figure 2. Representative reverse-phase HPLC chromatograms of AA profiles. A = de Man, Rogosa, and Sharpe (MRS) medium supplemented with $10 \mathrm{~g} / \mathrm{L}$ of monosodium glutamate (MSG) before fermentation; B = MRS medium supplemented with $10 \mathrm{~g} / \mathrm{L}$ of MSG after 24-h fermentation by isolate NPS-QW-281; C = MRS medium supplemented with $10 \mathrm{~g} / \mathrm{L}$ of MSG after 24-h fermentation by $\mathrm{CO}_{2}$-producing Lactobacillus fermentum W8; D = 0.1 g/L of each of 21 AA; peaks: $1=$ aspartic acid; $2=$ glutamic acid; $3=$ asparagine; $4=$ glutamine + arginine; $5=$ serine; $6=$ threonine; $7=$ glycine; $8=$ alanine; $9=\gamma$-aminobutyric acid $($ GABA); $10=$ proline; $11=$ valine; $12=$ methionine; $13=$ isoleucine; $14=$ leucine; $15=$ tryptophan; $16=$ phenylalanine; $17=$ cysteine; $18=$ lysine; $19=$ histidine; $20=$ tyrosine. Color version available online.

electrophoresis are shown in Figure 3. The target length of partial $16 \mathrm{~S}$ rRNA gene is $\sim 1,465 \mathrm{bp}$. The BLAST analysis of 9 sequences of the $16 \mathrm{~S}$ rRNA gene indicated that these 9 isolates were genetically identified as $L$. brevis (Table 2). The GenBank accession numbers for the 9 sequences are from KF851331 to KF851339.

\section{DISCUSSION}

\section{Gas Release-Based Prescreening Is Associated with Bacterial Acid Resistance}

Several important acid resistance systems, such as the $\mathrm{F}_{0} \mathrm{~F}_{1}$-ATPase system for discharging $\mathrm{H}^{+}$, amino acid deiminase system for neutralizing $\mathrm{H}^{+}$, and amino acid decarboxylase system for reducing $\mathrm{H}^{+}$, have been well demonstrated in bacteria (Lu et al., 2013; Teixeira et al., 2014). In addition, it has been well documented that the glutamate-GABA system contributes cell availability and metabolic activity for LAB during acidic environments (De Biase and Pennacchietti, 2012). It is expected that acid-resistant bacteria may survive after exposure to acidic condition. With glutamate as the substrate in the medium, high GABA producers were able to survive in acidic conditions by reducing $\mathrm{H}^{+}$. Hence, high-GABA-producing LAB may be harvested after recovery by adjusting the $\mathrm{pH}$ to 4.0 for the test of gas release.

\section{Time- and MSG Concentration-Dependent Bioconversion of Glutamate by High GABA Producers}

Based on previous data on GABA production by $L$. brevis ( $\mathrm{Li}$ and Cao, 2010), all 9 isolates in the present study were considered high-GABA-producing $L$. brevis strains (Table 1). Production of GABA is closely associated with membranal glutamate/GABA antiporter and cytoplasmic glutamate decarboxylase, as well as intracellular and extracellular acidity (Ma et al., 2012). 
Table 1. Production of $\gamma$-aminobutyric acid (GABA; means \pm SD) by potential high GABA producers in de Man, Rogosa, and Sharpe (MRS) medium supplemented with various concentrations of monosodium glutamate (MSG) at $37^{\circ} \mathrm{C}$ for 24,48 , and $72 \mathrm{~h}$

\begin{tabular}{|c|c|c|c|c|}
\hline Isolate & $\begin{array}{l}\text { MSG } \\
(\mathrm{g} / \mathrm{L})\end{array}$ & \multicolumn{3}{|c|}{ GABA production $(\mathrm{g} / \mathrm{L})$} \\
\hline \multirow{3}{*}{ NPS-QW-145 } & 30 & $11.494 \pm 1.244$ & $18.258 \pm 2.234$ & $16.141 \pm 0.947$ \\
\hline & 50 & $11.357 \pm 0.628$ & $22.693 \pm 1.606$ & $22.358 \pm 2.302$ \\
\hline & 70 & $12.763 \pm 0.690$ & $23.402 \pm 1.866$ & $25.831 \pm 1.898$ \\
\hline \multirow{3}{*}{ NPS-QW-177 } & 30 & $10.533 \pm 0.758$ & $17.508 \pm 0.683$ & $15.705 \pm 0.877$ \\
\hline & 50 & $9.160 \pm 0.629$ & $21.949 \pm 1.486$ & $19.724 \pm 1.691$ \\
\hline & 70 & $10.844 \pm 0.874$ & $24.098 \pm 1.658$ & $23.316 \pm 2.760$ \\
\hline \multirow[t]{4}{*}{ NPS-QW-216 } & 0 & $0.343 \pm 0.045$ & $0.444 \pm 0.022$ & $0.388 \pm 0.052$ \\
\hline & 10 & $5.998 \pm 0.257$ & $6.515 \pm 0.291$ & $6.310 \pm 0.770$ \\
\hline & 30 & $10.158 \pm 0.860$ & $16.812 \pm 1.001$ & $16.286 \pm 1.365$ \\
\hline & 50 & $9.065 \pm 0.250$ & $20.171 \pm 1.494$ & $21.694 \pm 1.365$ \\
\hline NPS-QW-255 & 70 & $4.823 \pm 0.173$ & $15.405 \pm 0.677$ & $17.671 \pm 1.557$ \\
\hline \multirow[t]{5}{*}{ NPS-QW-281 } & 0 & $0.337 \pm 0.008$ & $0.326 \pm 0.022$ & $0.367 \pm 0.001$ \\
\hline & 10 & $6.420 \pm 0.188$ & $6.227 \pm 0.428$ & $6.094 \pm 0.463$ \\
\hline & 30 & $10.347 \pm 0.108$ & $16.293 \pm 1.756$ & $16.099 \pm 1.927$ \\
\hline & 50 & $9.802 \pm 0.557$ & $19.719 \pm 1.405$ & $21.775 \pm 1.857$ \\
\hline & 70 & $10.682 \pm 0.683$ & $22.089 \pm 1.270$ & $23.638 \pm 2.041$ \\
\hline \multirow[t]{5}{*}{ NPS-QW-171 } & 0 & $0.365 \pm 0.029$ & $0.300 \pm 0.006$ & $0.384 \pm 0.027$ \\
\hline & 10 & $5.815 \pm 0.183$ & $5.438 \pm 0.382$ & $5.971 \pm 0.165$ \\
\hline & 30 & $9.604 \pm 1.223$ & $14.387 \pm 0.962$ & $15.932 \pm 0.760$ \\
\hline & 50 & $8.103 \pm 0.835$ & $17.614 \pm 0.437$ & $19.810 \pm 0.954$ \\
\hline & 70 & $5.433 \pm 0.141$ & $16.087 \pm 1.319$ & $19.631 \pm 0.904$ \\
\hline \multirow[t]{2}{*}{ NPS-QW-193 } & 0 & $0.384 \pm 0.006$ & $0.381 \pm 0.013$ & $0.357 \pm 0.029$ \\
\hline & 10 & $6.118 \pm 0.709$ & $6.729 \pm 0.402$ & $6.029 \pm 0.459$ \\
\hline \multirow{3}{*}{ NPS-QW-267 } & 30 & $9.532 \pm 0.529$ & $16.857 \pm 0.620$ & $16.064 \pm 0.338$ \\
\hline & 50 & $8.410 \pm 0.124$ & $19.464 \pm 1.754$ & $19.872 \pm 2.365$ \\
\hline & 70 & $9.216 \pm 0.160$ & $21.825 \pm 1.187$ & $24.992 \pm 2.334$ \\
\hline \multirow[t]{5}{*}{ Calculation of $100 \%$ conversion $^{1}$} & 0 & & 0 & \\
\hline & 10 & & 6.09 & \\
\hline & 30 & & 18.29 & \\
\hline & 50 & & 30.54 & \\
\hline & 70 & & 42.63 & \\
\hline
\end{tabular}

${ }^{1} 100 \%$ conversion indicates that the MSG supplemented in MRS broth was completely converted into GABA.

As mentioned above, decarboxylation helps reduce intracellular $\mathrm{H}^{+}$to maintain cellular viability during acidic conditions. As seen in Table 1, production of GABA increased during $72 \mathrm{~h}$ of fermentation with higher concentrations of MSG (50 and $70 \mathrm{~g} / \mathrm{L}$ ), whereas MSG was almost converted into GABA within $72 \mathrm{~h}$ at lower concentrations of MSG (e.g., 10 and $30 \mathrm{~g} / \mathrm{L}$ ). A decrease in the concentration of GABA was observed for most strains at $72 \mathrm{~h}$ compared with that at $48 \mathrm{~h}$, which may be related to degradation by GABA aminotransferase in L. brevis (Le Vo et al., 2012). Moreover, GABA yields from a GABA producer varied at the same time in MRS broth containing different concentrations of MSG (Table 1). This may suggest that increased $\mathrm{Na}^{+}$ 


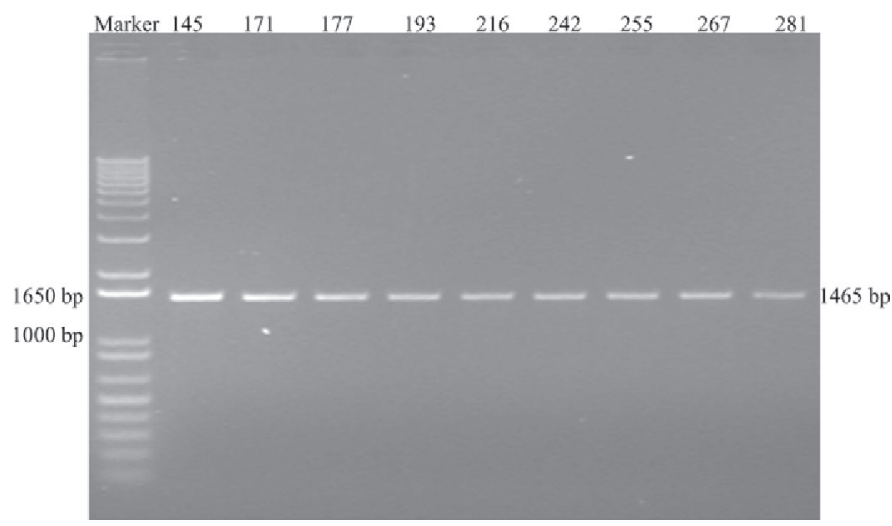

Figure 3. Agarose gel electrophoresis of PCR products of $16 \mathrm{~S}$ rRNA gene of 9 high $\gamma$-aminobutyric acid (GABA) producers.

from MSG affected cell viability and GABA production (Gandhi and Shah, 2014). Interestingly, we found that all potential high GABA producers were able to produce GABA in MRS medium without the addition of MSG. This occurred mainly because of the release of glutamate from proteins in the medium by bacterial proteolysis.

\section{Accuracy of Gas Release-Based Prescreening of High GABA Producers}

The gas from MRS medium after incubation could be $\mathrm{CO}_{2}$ via heterofermentation of glucose or decarboxylation of glutamate or could beNH $\mathrm{H}_{3}$ production via deamination of AA (Mayo et al., 2010; Lu et al., 2013; Teixeira et al., 2014). However, the smell of released gas in the present study was not pungent, indicating that the main component of gas was $\mathrm{CO}_{2}$. It has been well documented that heterofermentative LAB are able to ferment glucose and lactose with lactic acid, acetic acid, ethanol, and $\mathrm{CO}_{2}$ as by-products (Mayo et al., 2010). In present study, the LAB producing $\mathrm{CO}_{2}$ could be high GABA producers or could be heterofermentative LAB. Based on the AA profiles of high GABA producers and $\mathrm{CO}_{2}$-producing L. fermentum W8 (chro- matograms B and C, Figure 2), gas release was not a completely accurate method to identify high GABA producers. Although this prescreening seems to be empirical (based on visual observation), prescreening based on gas release is a way to identify potential high GABA producers.

\section{Efficiency of Gas Release-Based Prescreening Combined with HPLC Confirmation}

We compared our screening method with other methods, as shown in Table 3. In the present study, 9 isolates from 500 randomly selected colonies were identified as potential high GABA producers based on gas release and were further confirmed as high GABA producers by HPLC. Thus, efficiency from the prescreening step to HPLC confirmation was $100 \%$ because all potential high GABA producers were identified as high GABA producers after HPLC confirmation, which was very efficient compared with other methods (Table 3). In general, LAB isolates were individually cultured in MRS broth containing certain concentration of MSG before the prescreening step. Although prescreening based on observation of gas release may not be able to select LAB isolates that produce low levels of GABA, the method is efficient, rapid, simple, and cost effective compared with time-consuming and expensive chromatographybased prescreening techniques such as TLC and HPLC.

\section{CONCLUSIONS}

A high-throughput, rapid, simple, and cost-effective method for screening potential high GABA producers was developed based on gas release from Korean kimchi, and the GABA-producing capacity of these strains was confirmed by HPLC. In total, 9 LAB isolates were confirmed as high GABA producers by reversed-phase HPLC. These strains were genetically identified as $L$. brevis by $16 \mathrm{~S}$ rRNA gene identification. This study provides a new method for screening high-GABA-producing LAB, which could be good candidates for probi-

Table 2. Alignment results of sequences of 16S rRNA gene of 9 high $\gamma$-aminobutyric acid (GABA) producers

\begin{tabular}{llcl}
\hline Isolate & Closest species & Similarity (\%) & $\begin{array}{l}\text { GenBank Accession No. } \\
\text { (reference sequence) }\end{array}$ \\
\hline NPS-QW-145 & Lactobacillus brevis & 99 & AP012167.1 \\
NPS-QW-171 & Lactobacillus brevis & 99 & AP012167.1 \\
NPS-QW-177 & Lactobacillus brevis & 99 & AP012167.1 \\
NPS-QW-193 & Lactobacillus brevis & 99 & AP012167.1 \\
NPS-QW-216 & Lactobacillus brevis & 99 & AP012167.1 \\
NPS-QW-242 & Lactobacillus brevis & 99 & AP012167.1 \\
NPS-QW-255 & Lactobacillus brevis & 99 & AP012167.1 \\
NPS-QW-267 & Lactobacillus brevis & 99 & AP012167.1 \\
NPS-QW-281 & Lactobacillus brevis & 99 & AP012167.1 \\
\hline
\end{tabular}




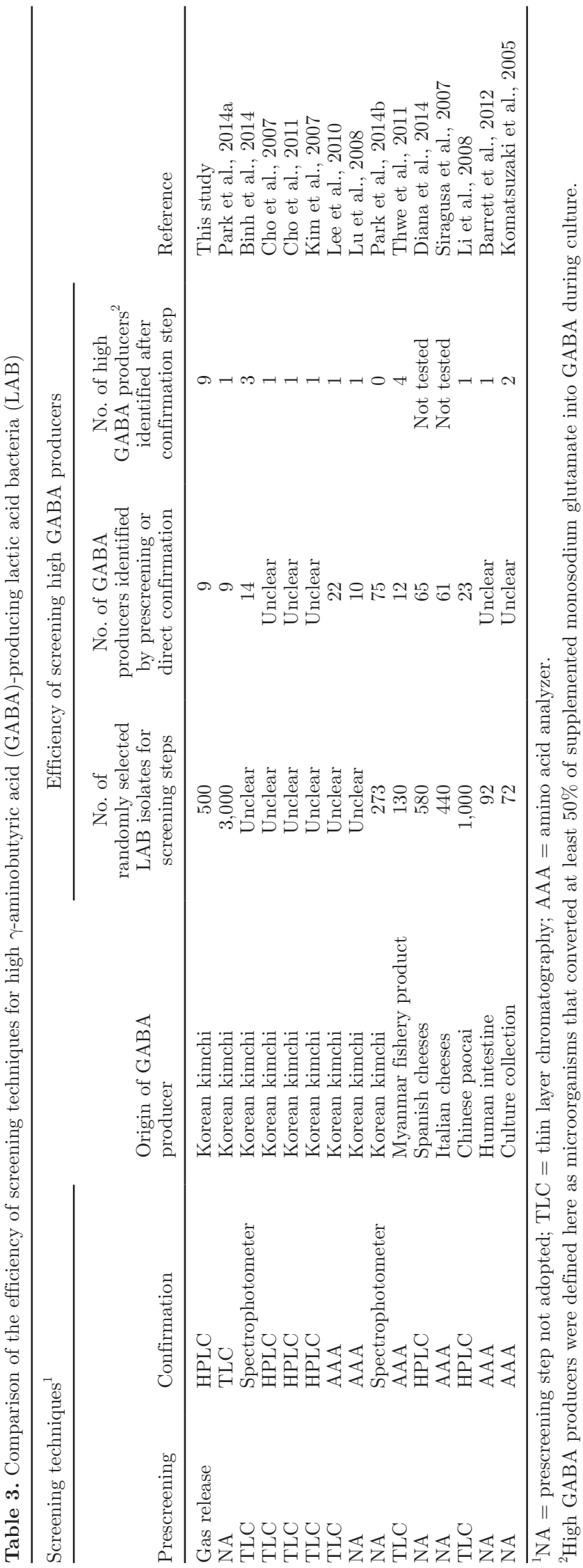

otics. These high-GABA-producing LAB isolates could be used as cell factories for manufacturing GRAS-grade GABA from food-grade bacteria.

\section{ACKNOWLEDGMENTS}

We thank Hua Wei from State Key Laboratory of Food Science and Technology (Nanchang University, China) for providing high- $\mathrm{CO}_{2}$-producing Lactobacillus fermentum W8.

\section{REFERENCES}

Barrett, E., R. P. Ross, P. W. O'Toole, G. F. Fitzgerald, and C. Stanton. 2012. Gamma-aminobutyric acid production by culturable bacteria from the human intestine. J. Appl. Microbiol. 113:411417.

Binh, T. T. T., W. T. Ju, W. J. Jung, and R. D. Park. 2014. Optimization of gamma-amino butyric acid production in a newly isolated Lactobacillus brevis. Biotechnol. Lett. 36:93-98.

Cho, S. Y., M. J. Park, K. M. Kim, J. H. Ryu, and H. J. Park. 2011. Production of high gamma-aminobutyric acid (GABA) sour kimchi using lactic acid bacteria isolated from mukeunjee kimchi. Food Sci. Biotechnol. 20:403-408.

Cho, Y. R., J. Y. Chang, and H. C. Chang. 2007. Production of gamma-aminobutyric acid (GABA) by Lactobacillus buchneri isolated from kimchi and its neuroprotective effect on neuronal cells. J. Microbiol. Biotechnol. 17:104-109.

Chuang, C. Y., Y. C. Shi, H. P. You, Y. H. Lo, and T. M. Pan. 2011. Antidepressant effect of GABA-rich monascus-fermented product on forced swimming rat model. J. Agric. Food Chem. 59:30273034

Constantin, S., C. L. Jasoni, B. Wadas, and A. E. Herbison. 2010. Gamma-aminobutyric acid and glutamate differentially regulate intracellular calcium concentrations in mouse gonadotropin-releasing hormone neurons. Endocrinology 151:262-270.

Cryan, J. F., and K. Kaupmann. 2005. Don't worry 'B' happy!: A role for $\mathrm{GABA}(\mathrm{B})$ receptors in anxiety and depression. Trends Pharmacol. Sci. 26:36-43.

De Biase, D., and E. Pennacchietti. 2012. Glutamate decarboxylasedependent acid resistance in orally acquired bacteria: Function, distribution and biomedical implications of the gadBC operon. Mol. Microbiol. 86:770-786.

Diana, M., A. Tres, J. Quilez, M. Llombart, and M. Rafecas. 2014 Spanish cheese screening and selection of lactic acid bacteria with high gamma-aminobutyric acid production. Lebenson. Wiss. Technol. 56:351-355.

Fan, E. Y., J. Huang, S. Hu, L. H. Mei, and K. Yu. 2012. Cloning, sequencing and expression of a glutamate decarboxylase gene from the GABA-producing strain Lactobacillus brevis CGMCC 1306. Ann. Microbiol. 62:689-698.

Gamel-Didelon, K., C. Corsi, G. Pepeu, H. Jung, M. Gratzl, and A. Mayerhofer. 2002. An autocrine role for pituitary GABA: Activation of GABA-B receptors and regulation of growth hormone levels. Neuroendocrinology 76:170-177.

Gandhi, A., and N. P. Shah. 2014. Effects of salt concentration and $\mathrm{pH}$ on structural and functional properties of Lactobacillus acidophilus: FT-IR spectroscopic analysis. Int. J. Food Microbiol. 173:41-47.

Hayakawa, K., M. Kimura, and K. Kamata. 2002. Mechanism underlying gamma-aminobutyric acid-induced antihypertensive effect in spontaneously hypertensive rats. Eur. J. Pharmacol. 438:107-113.

Inoue, K., T. Shirai, H. Ochiai, M. Kasao, K. Hayakawa, M. Kimura, and H. Sansawa. 2003. Blood-pressure-lowering effect of a novel fermented milk containing gamma-aminobutyric acid (GABA) in mild hypertensives. Eur. J. Clin. Nutr. 57:490-495. 
Kim, S. H., B. H. Shin, Y. H. Kim, S. W. Nam, and S. J. Jeon. 2007. Cloning and expression of a full-length glutamate decarboxylase gene from Lactobacillus brevis BH2. Biotechnol. Bioproc. Eng. 12:707-712.

Komatsuzaki, N., J. Shima, S. Kawamoto, H. Momose, and T. Kimura. 2005. Production of gamma-aminobutyric acid (GABA) by Lactobacillus paracasei isolated from traditional fermented foods. Food Microbiol. 22:497-504.

Krystal, J. H., G. Sanacora, H. Blumberg, A. Anand, D. S. Charney, G. Marek, C. N. Epperson, A. Goddard, and G. F. Mason. 2002. Glutamate and GABA systems as targets for novel antidepressant and mood-stabilizing treatments. Mol. Psychiatry 7:S71-S80.

Le Vo, T. D., T. W. Kim, and S. H. Hong. 2012. Effects of glutamate decarboxylase and gamma-aminobutyric acid (GABA) transporter on the bioconversion of GABA in engineered Escherichia coli. Bioprocess Biosyst. Eng. 35:645-650.

Lee, B. J., J. S. Kim, Y. M. Kang, J. H. Lim, Y. M. Kim, M. S. Lee, M. H. Jeong, C. B. Ahn, and J. Y. Je. 2010. Antioxidant activity and gamma-aminobutyric acid (GABA) content in sea tangle fermented by Lactobacillus brevis BJ20 isolated from traditional fermented foods. Food Chem. 122:271-276.

Li, H. X., and Y. S. Cao. 2010. Lactic acid bacterial cell factories for gamma-aminobutyric acid. Amino Acids 39:1107-1116.

Li, H. X., D. D. Gao, Y. S. Cao, and H. Y. Xu. 2008. A high gammaaminobutyric acid-producing Lactobacillus brevis isolated from Chinese traditional paocai. Ann. Microbiol. 58:649-653.

Liu, C. F., Y. T. Tung, C. L. Wu, B. H. Lee, W. H. Hsu, and T. M. Pan. 2011. Antihypertensive effects of Lactobacillus-fermented milk orally administered to spontaneously hypertensive rats. J. Agric. Food Chem. 59:4537-4543.

Lu, P. L., D. Ma, Y. L. Chen, Y. Y. Guo, G. Q. Chen, H. T. Deng, and Y. G. Shi. 2013. L-glutamine provides acid resistance for Escherichia coli through enzymatic release of ammonia. Cell Res. 23:635-644.

Lu, X. X., Z. G. Chen, Z. X. Gu, and Y. B. Han. 2008. Isolation of gamma-aminobutyric acid-producing bacteria and optimization of fermentative medium. Biochem. Eng. J. 41:48-52.

Ma, D., P. L. Lu, C. Y. Yan, C. Fan, P. Yin, J. W. Wang, and Y. G. Shi. 2012. Structure and mechanism of a glutamate-GABA antiporter. Nature 483:632-636.

Marchesi, J. R., T. Sato, A. J. Weightman, T. A. Martin, J. C. Fry, S. J. Hiom, and W. G. Wade. 1998. Design and evaluation of useful bacterium-specific PCR primers that amplify genes coding for bacterial 16S rRNA. Appl. Environ. Microbiol. 64:795-799.

Mayo, B., A. Aleksandrzak-Piekarczyk, M. Fernández, M. Kowalczyk, P. Álvarez-Martín, and J. Bardowski. 2010. Updates in the metabolism of lactic acid bacteria. Pages 3-33 in Biotechnology of Lactic Acid Bacteria Novel Applications. F. Mozzi, R. R. Raya, and G. M. Vignolo, ed. John Wiley \& Sons, New York, NY.

Nejati, F., C. G. Rizzello, R. Di Cagno, M. Sheikh-Zeinoddin, A. Diviccaro, F. Minervini, and M. Gobbett. 2013. Manufacture of a functional fermented milk enriched of angiotensin-I converting enzyme (ACE)-inhibitory peptides and gamma-amino butyric acid (GABA). Lebenson. Wiss. Technol. 51:183-189.

Park, J. Y., S. J. Jeong, and J. H. Kim. 2014a. Characterization of a glutamate decarboxylase (GAD) gene from Lactobacillus zymae. Biotechnol. Lett. 36:1791-1799.

Park, K. B., and S. H. Oh. 2007. Cloning, sequencing and expression of a novel glutamate decarboxylase gene from a newly isolated lactic acid bacterium, Lactobacillus brevis OPK-3. Bioresour. Technol. 98:312-319.

Park, S. Y., J. W. Lee, and S. D. Lim. 2014b. The probiotic characteristics and GABA production of Lactobacillus plantarum K154 isolated from kimchi. Food Sci. Biotechnol. 23:1951-1957.

Rizzello, C. G., A. Cassone, R. Di Cagno, and M. Gobbetti. 2008. Synthesis of angiotensin I-converting enzyme (ACE)-inhibitory peptides and gamma-aminobutyric acid (GABA) during sourdough fermentation by selected lactic acid bacteria. J. Agric. Food Chem. 56:6936-6943.

Siragusa, S., M. De Angelis, R. Di Cagno, C. G. Rizzello, R. Coda, and M. Gobbetti. 2007. Synthesis of gamma-aminobutyric acid by lactic acid bacteria isolated from a variety of Italian cheeses. Appl. Environ. Microbiol. 73:7283-7290.

Sun, T. S., S. P. Zhao, H. K. Wang, C. K. Cai, Y. F. Chen, and H. P. Zhang. 2009. ACE-inhibitory activity and gamma-aminobutyric acid content of fermented skim milk by Lactobacillus helveticus isolated from Xinjiang koumiss in China. Eur. Food Res. Technol. 228:607-612.

Teixeira, J. S., A. Seeras, A. F. Sanchez-Maldonado, C. Zhang, M. S. $\mathrm{Su}$, and M. G. Gänzle. 2014. Glutamine, glutamate, and argininebased acid resistance in Lactobacillus reuteri. Food Microbiol. 42:172-180.

Thwe, S. M., T. Kobayashi, T. Luan, T. Shirai, M. Onodera, N. Hamada-Sato, and C. Imada. 2011. Isolation, characterization, and utilization of gamma-aminobutyric acid (GABA)-producing lactic acid bacteria from Myanmar fishery products fermented with boiled rice. Fish. Sci. 77:279-288.

Yokoyama, S., J. I. Hiramatsu, and K. Hayakawa. 2002. Production of gamma-aminobutyric acid from alcohol distillery lees by Lactobacillus brevis IFO-12005. J. Biosci. Bioeng. 93:95-97.

Yoshimura, M., T. Toyoshi, A. Sano, T. Izumi, T. Fujii, C. Konishi, S. Inai, C. Matsukura, N. Fukuda, H. Ezura, and A. Obata. 2010. Antihypertensive effect of a gamma-aminobutyric acid rich tomato cultivar 'DG03-9' in spontaneously hypertensive rats. J. Agric. Food Chem. 58:615-619.

Zhang, Y., L. Song, Q. Gao, S. M. Yu, L. Li, and N. F. Gao. 2012. The two-step biotransformation of monosodium glutamate to GABA by Lactobacillus brevis growing and resting cells. Appl. Microbiol. Biotechnol. 94:1619-1627. 